\title{
Nutrition, Sex, and Fetal Lung Maturation
}

\author{
Richard L. Naeye, ${ }^{[20]}$ Roger K. Freeman, and William A. Blanc \\ Department of Pathology, Pennsylvania State University College of Medicine, Hershey, Pennsylvania; Department of Obstetrics and \\ Gynecology, University of Southern California School of Medicine, Los Angeles, California; Department of Pathology, \\ Columbia University, College of Physicians and Surgeons, New York City, New York, USA
}

\begin{abstract}
Extract
Maternal nutrition and the sex of a fetus appear to have important influences on fetal lung maturation and on the neonatal development of hyaline membrane disease. Amniotic fluid lecithin to sphingomyelin ratios and shake test values were greater in undernourished than in overnourished pregnancies after midgestation. There was a similar relation between levels of maternal nutrition and structural variables of fetal lung maturity. Using the same variables, the lungs of female fetuses matured somewhat more rapidly than the lungs of males. Hyaline membrane disease was almost twice as common in infants who died after overnourished gestations as in those who had undernourished mothers.
\end{abstract}

\section{Speculation}

The study should not be used as the basis for recommendations to restrict food intake during pregnancy. Research is needed to determine whether calories alone or the balance between calories and other specific nutrients are able to influence the rate of fetal lung maturation.

\section{Introduction}

It has long been known that hyaline membrane disease is more common in male than in female neonates [14]. By contrast, maternal nutrition has not been considered an important factor in the genesis of the disorder. The present study has found that both maternal nutrition and the sex of a fetus affect the pace at which fetal lungs mature.

\section{Patients}

Material was reviewed from 1,044 consecutive autopsies on well preserved stillborn and newborn infants examined at Babies Hospital, New York City, between 1960 and 1968. Cases were first excluded which had any non-nutritional fetal or maternal disorder known to influence pregnancy weight gain, fetal or placental growth, amniotic fluid volume, or extracellular fluid volume of the mother, i.e., major fetal congenital anomalies, chromosomal disorders, chronic congenital infections of any type, major placental lesions, multiple births, infants of diabetic mothers or narcotic addicts, gestations with hydramnios, oligohydramnios, $\mathrm{Rh}$ disease, maternal hypertension, or other evidences of toxemia of pregnancy.

Of the remaining cases, the proportions with hyaline membrane disease and cerebral intraventricular hemorrhage were calculated for subgroups of 241 liveborn infants who were less than 36 weeks of gestational age and lived longer than $6 \mathrm{hr}$ but less than $72 \mathrm{hr}, 6 \mathrm{hr}$ being chosen because the anatomic features of hyaline membrane disease are usually well developed by this time. Of the other remaining cases, 323 were stillborn or lived less than $1 \mathrm{hr}$ and hence were suitable for a histologic analysis of their lung maturity. Histologic variables of lung maturity change very rapidly after 
birth, so that older infants are not suitable for the type of analysis used in the current study.

Two-thirds of the mothers received general dietary advice to avoid sweets, salty foods, and food between meals. The remaining mothers were referred to a dietician and placed on specific 1,200 and 1,500 calorie diets for the final months of pregnancy [13]. These low calorie diets had adequate protein, vitamins, and minerals [13]. The diets were usually prescribed to slow excessive weight gain. They often achieved their goals because the total weight gain for such pregnancies often proved to be less than 20 pounds.

Also included in the study were amniotic fluid analyses from 180 apparently normal pregnancies at the Los Angeles County, University of Southern California Medical Center and 40 normal pregnancies at Sloan Hospital for Women, New York City. Most of these amniotic fluid examinations were undertaken to help determine the best time for repeat caesarean section.

\section{Methods}

An effort was made to analyze the role of maternal gestational nutrition on fetal lung maturation and on the subsequent development of hyaline membrane disease. A recent study from our laboratory found that maternal nutrition as reflected by pregravid body weight, diet, and weight gain during pregnancy, had an important influence on fetal body and organ growth [13]. By contrast, height, race, economic status, age, work, marital status, and interval since last pregnancy had no influence on fetal growth independent of maternal nutrition [13].

In the current study, mother's weight for height was used as a measure of immediate prepregnancy nutritional status. Individual mothers were classified as overweight or underweight at the start of pregnancy by being above or below standard weight for height in tables published by the World Health Organization [8]. Nutritional status during pregnancy was assessed by analyzing maternal weight gain. Several studies have shown a relation between caloric intake in pregnancy and maternal weight gain [1]. Inasmuch as a 24-27 pound weight gain correlates with optimal outcome for a full term gestation, average weight gains in full term cases were classified as high or low on the basis of being greater or less than 27 pounds $(310 \mathrm{~g} /$ week) [7, 15]. Based on a 27-pound weight gain at term, Hytten and Leitch [7] found the optimal gain to be 8.5 pounds at 20 weeks (185 g/week) and 19 pounds at 30 weeks (283 $\mathrm{g} /$ week). Using these and intermediate values, we classified maternal weight gains as high or low for all cases. The weight gain actually used for individual gram per week calculations was the one recorded at the last clinic visit before delivery so that any acute events related to labor would not influence the weight gain classification.

Mothers were placed in nutritional category 1 if they were overweight at the start of pregnancy and had gained more than the Hytten and Leitch optimal weight for their gestational period [7, 13]. Nutritional category 2 included those underweight before pregnancy who had more than an optimal weight gain. Category 3 consisted of overweight mothers with a suboptimal weight gain, and category 4 contained underweight mothers who had a suboptimal weight gain.

Platt's histologic classifications were used to grade the structural maturity of the lungs of neonates (Table I) [16]. These examinations and classifications were made by a single person without knowledge of a mother's nutritional status or an infant's sex. Both the shake test and the lecithin to sphingomyelin $(\mathrm{L} / \mathrm{S})$ concentration ratio in amniotic fluid have proved to be accurate methods of assessing fetal lung maturity before birth $[2,5]$. Such L/S data were available for 180 apparently normal pregnancies at the Los Angeles County Medical Center and for 40 normal pregnancies at Sloan Hospital. Mean L/S ratios were virtually identical for cases of the same gestational age and nutritional category at the two institutions, therefore their $\mathrm{L} / \mathrm{S}$ data were pooled in the final analyses. Shake test data were available for the Los Angeles but not the New York City

Table $I$. Platt's classification of fetal lung maturation based on light microscopy [16]

Lung $\quad$ Stage

Continuous layer of cells, abundant mesenchyme, few capillaries

Continuous layer of cuboidal cells, abundant mesenchyme, increased numbers of capillaries, some adjacent but not penetrating the cuboidal layer

Cuboidal layer continuous in some ducts but in others a few capillaries have encroached between the cuboidal cells and are in contact with the lumen; abundant mesenchyme

Cuboidal layer not continuous and moderate numbers of capillaries penetrate and contact lumen; mesenchyme reduced

Few cuboidal cells still present; numerous capillaries and mesenchyme reduced to 3-6 cells thick

Mature form; no cuboidal cells, numerous capillaries and mesenchyme reduced to 3 or less cells in thickness; alveolar duct development complete 
cases. Four tubes were used for each shake test and the findings in each tube were graded from 0 to 3 for a maximum score of 12. A tube was scored 0 if there were no bubbles, I if bubbles encompassed less than half the ring of fluid-tube interface, 2 if more than half, and 3 if the entire interface had bubbles.

Hyaline membrane disease was diagnosed when lungs were solid and airless and had eosinophilic membranes with widespread microscopic atelectasis alternating with isolated overdistended alveoli and alveolar ducts. Diagnostic criteria for other disorders have been previously published [14].

Table II. Relation of maternal nutrition to fetal lung maturation using histologic index of Platt [16 $]^{1}$

\begin{tabular}{|c|c|c|c|c|}
\hline \multirow{2}{*}{$\begin{array}{l}\text { Gestational } \\
\text { age, } \\
\text { weeks }\end{array}$} & \multicolumn{4}{|c|}{ Nutritional category } \\
\hline & 1 & 2 & 3 & 4 \\
\hline $20-24$ & $\begin{array}{c}2.4 \pm 1.1 \\
(13)\end{array}$ & $\underset{(21)}{3.0 \pm 1.0^{2}}$ & $\underset{(18)}{2.7 \pm 1.0}$ & ${ }_{(16)}^{3.5 \pm 1.2^{2}}$ \\
\hline $25-27$ & $\begin{array}{c}3.6 \pm 0.8 \\
(11)\end{array}$ & $\begin{array}{c}3.8 \pm 1.0 \\
(25)\end{array}$ & $\begin{array}{c}3.7 \pm 0.6 \\
(14)\end{array}$ & $\begin{array}{c}3.9 \pm 1.0 \\
(21)\end{array}$ \\
\hline $28-32$ & $\begin{array}{c}4.7 \pm 0.4 \\
(16)\end{array}$ & $\begin{array}{c}4.9 \underset{(28)}{ \pm} 0.8 \\
\text { (28) }\end{array}$ & $\begin{array}{c}4.3 \pm 1.0 \\
(21)\end{array}$ & $5.0 \pm 1.0^{2}$ \\
\hline Over 32 & $\begin{array}{c}5.6 \pm 0.2 \\
(24)\end{array}$ & $\begin{array}{c}5.9 \pm 0.2 \\
(23)\end{array}$ & $\begin{array}{c}6.0 \pm 0 \\
(21)\end{array}$ & $\begin{array}{c}6.0 \pm 0^{2} \\
(28)\end{array}$ \\
\hline
\end{tabular}

${ }_{1}$ All values are $\pm 1 \mathrm{sD}$. Number of cases are shown in parentheses.

$2 P<0.05$ by comparison with mean of nutritional category 1 . None of the differences between the means of other categories are statistically significant.

\section{Results}

At each gestational age, offspring of the most poorly nourished mothers had structurally more mature lungs than did neonates of better nourished mothers (Table II). Results were similar for amniotic fluid $\mathrm{L} / \mathrm{S}$ ratios and shake tests (Table III). The sex of the fetus had a smaller but significant influence on lung maturation. This was most evident in the analysis of structural variables; the lungs of females were more mature than the lungs of males at each gestational age (Fig. 1). The $\mathrm{L} / \mathrm{S}$ and shake test values were approximately $5 \%$ greater for females than for males at each gestational age; this difference was not statistically significant. The two sexes had a similar distribution of cases in the various nutritional categories.

Among infants who died from overnourished mothers (nutritional category 1), the proportion who had hyaline membrane disease was almost double that of offspring from undernourished mothers (nutritional category 4) (Table IV). In each nutritional category, the proportion who had hyaline membrane disease was lower in offspring of mothers who had been on low calorie diets before delivery (Table IV). This was not true of several other disease processes (Table IV). The mean gestational age was virtually identical for infants in the various nutritional subgroups of this table. Table III. Relation of maternal nutrition to fetal lung maturation using lecithin to sphingomyelin ratio (L/S ratio) of Gluck and the
shake test of Clements $[2,5]^{1}$

\begin{tabular}{|c|c|c|c|c|}
\hline \multirow{2}{*}{$\begin{array}{c}\text { Gestational age, } \\
\text { weeks }\end{array}$} & \multicolumn{4}{|c|}{ Nutritional category } \\
\hline & 1 & 2 & 3 & 4 \\
\hline \multicolumn{5}{|l|}{$\mathrm{L} / \mathrm{S}$ ratios } \\
\hline $25-34$ & $1.48 \pm 0.41$ & $1.70 \pm 0.30$ & $1.71 \pm 0.81$ & $2.88 \pm 0.84^{2,3,4}(10)$ \\
\hline $35-37$ & $2.04 \pm 0.95$ & $2.86 \pm 1.20^{2}(17)$ & $2.60 \pm 1.06$ & $4.29 \pm 1.68^{2,3,4}$ \\
\hline 38-39 & $2.55 \pm 1.20$ & $3.25 \pm 1.06^{2}(13)$ & $3.20 \pm 1.17$ & $4.61 \pm 0.41^{2,3,4}(9)$ \\
\hline $\begin{array}{l}40 \text { and over } \\
\text { Shake tests }\end{array}$ & $3.18 \pm 1.24$ & $3.70 \pm 0.86^{2}$ & $3.32 \pm 1.45(20)$ & $4.39 \pm 0.62^{2,3,4}(13)$ \\
\hline $25-34$ & $0.9 \pm 0.8$ & $1.7 \pm 1.1$ & $2.4 \pm 2.0^{2}(11)$ & $4.2 \pm 2.4^{2,3}$ \\
\hline $35-37$ & $2.5 \pm 3.7(19)$ & $3.3 \pm 3.7$ & $5.9 \pm 3.4^{2}(26)$ & $8.3 \pm 3.9^{2,3}(9)$ \\
\hline $38-39$ & $3.6 \pm 3.4(20)$ & $5.7 \pm 3.4(10)$ & $4.8 \pm 4.7$ & $8.0 \pm 2.5^{2,3,4}(6)$ \\
\hline 40 and over & $5.8 \pm 3.9(24)$ & $8.7 \pm 3.1^{2}(11)$ & $6.1 \pm 3.9^{3}$ & $8.4 \pm 1.5^{2,3}(8)$ \\
\hline
\end{tabular}

1 All values are $\pm 1 \mathrm{sD}$. Number of cases are shown in parentheses.

${ }^{2} P<0.05$ by comparison with nutritional category 1 .

${ }^{3} P<0.05$ by comparison with nutritional category 2 .

${ }^{4} P<0.05$ by comparison with nutritional category 3 . 


\section{Discussion}

The present study confirms the unpublished histologic findings of Platt that the lungs of human female fetuses mature somewhat more rapidly than do the lungs of males [16]. Similar but statistically insignificant differences were found in biochemical variables of lung maturation. These differences between the sexes are probably not great enough to explain most of the often reported higher incidence of neonatal hyaline membrane disease in males than in females $[14,17]$.

The finding that fetal lung maturation is most rapid in offspring of poorly nourished mothers may help to explain the observation of Gluck et al. [4], that preg. nancies complicated by reduced placental function often have neonates with accelerated lung maturity for gestational age. Both reduced placental function and maternal undernutrition often lead to fetal undernutrition $[10,11,13]$. Hormones might mediate the nutri-

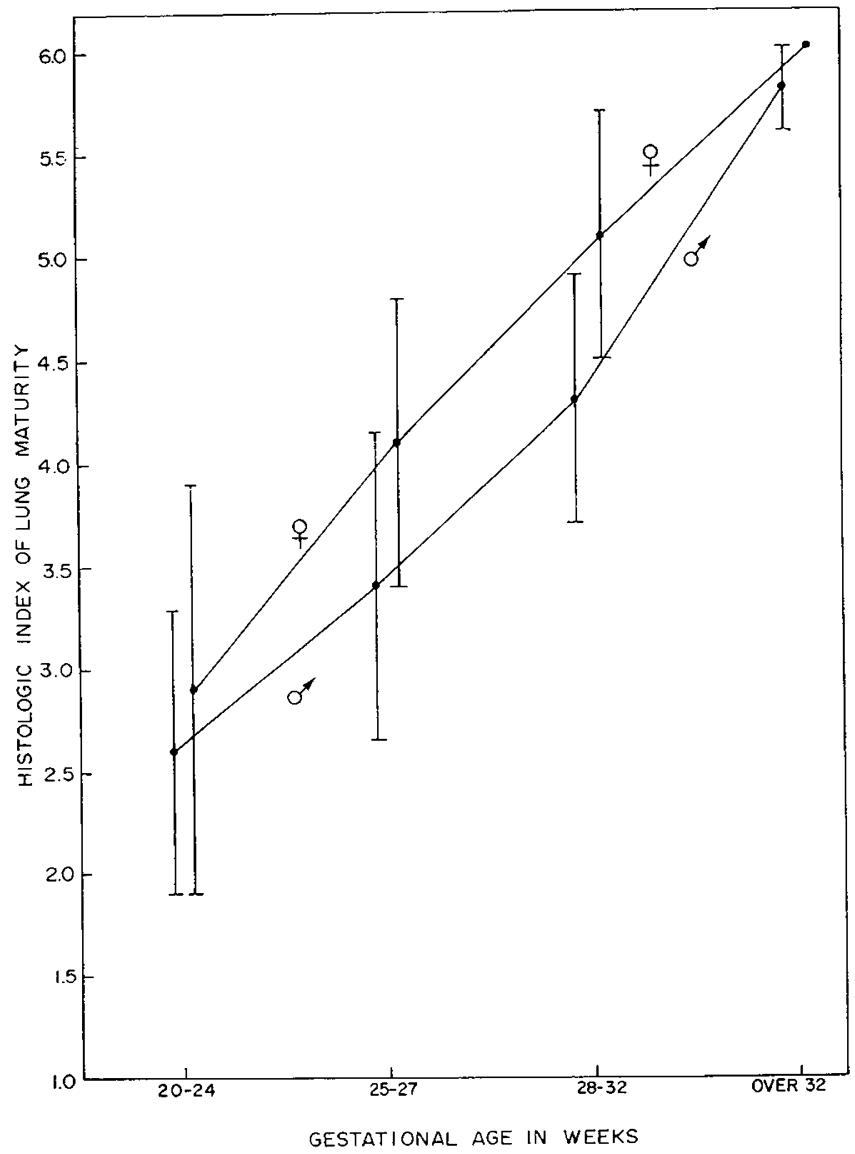

Fig. 1. Histologic index of lung maturity at various gestational ages. The lungs of female fetuses mature at a more rapid rate than those of males. The vertical bar at each datum point represents $1 \mathrm{sD}$.
Table IV. Percentage of cases with major diseases in offspring of mothers in various nutritional categories ${ }^{1}$

\begin{tabular}{|c|c|c|c|c|c|c|}
\hline $\begin{array}{l}\text { Maternal } \\
\text { nuttitional } \\
\text { categories }\end{array}$ & $\begin{array}{c}\text { Hyaline } \\
\text { membrane } \\
\text { disease, } \\
\% \%\end{array}$ & $\begin{array}{c}\text { Amniotic } \\
\text { fluid } \\
\text { infec- } \\
\text { tion } \\
\text { syn- } \\
\text { drome, } \\
\%\end{array}$ & $\begin{array}{l}\text { Fetal } \\
\text { hy- } \\
\text { poxia, } \\
\%\end{array}$ & $\begin{array}{c}\text { Pulmo- } \\
\text { nary } \\
\text { alveo- } \\
\text { lar } \\
\text { hemor- } \\
\text { rhage, } \\
\%\end{array}$ & $\begin{array}{l}\text { Intra- } \\
\text { ventri- } \\
\text { cular } \\
\text { and } \\
\text { subara- } \\
\text { chnoid } \\
\text { hemor- } \\
\text { rhage, } \\
\% \%\end{array}$ & $\begin{array}{l}\text { Mean } \\
\text { gesta- } \\
\text { tional } \\
\text { age, } \\
\text { weeks }\end{array}$ \\
\hline \multicolumn{7}{|l|}{ Category 1} \\
\hline No diet & $46(13)$ & 40 & 21 & 15 & 27 & 31 \\
\hline Low calorie & $30(7)$ & 46 & 26 & 4 & 31 & 30 \\
\hline \multicolumn{7}{|l|}{ Category 2} \\
\hline No diet & $34(13)$ & 34 & 30 & 7 & 27 & 30 \\
\hline Low calorie & $29(4)$ & 40 & 17 & 0 & 25 & 31 \\
\hline \multicolumn{7}{|l|}{ Category 3} \\
\hline No diet & $34(17)$ & 41 & 29 & 10 & 28 & 32 \\
\hline Low calorie & $23(7)$ & 38 & 44 & 3 & 28 & 29 \\
\hline \multicolumn{7}{|l|}{ Category 4} \\
\hline No diet & $26(12)$ & 42 & 25 & 8 & 22 & 31 \\
\hline Low calorie & $18(2)$ & 45 & 32 & 14 & 28 & 32 \\
\hline
\end{tabular}

1 In hyaline membrane disease, pulmonary alveolar hemorrhage, and in traven tricular hemorrhage categories, only infants under 36 weeks of gestational age and living longer than $6 \mathrm{hr}$ but less than $72 \mathrm{hr}$ are included. $P<0.05$ for table of hyaline membrane disease values as a whole (chi square). $P$ values for other tables of disease processes $>0.05$. The number of cases with hyaline membrane disease are shown in parentheses.

tional effects on lung maturation. Turnover rates of corticosteroids and the balance between such corticosteroids and other hormones are abnormal in experimental malnutrition [6]; corticosteroids have been shown to accelerate fetal lung maturation in both human beings and experimental animals [3, 9].

Certain cautions should be observed in interpreting the current data. The study should not be used as the basis for recommendations to restrict food intake during pregnancy. Only the most poorly nourished gestations showed an impressive acceleration of fetal lung maturation and there is published evidence that marked food restriction during pregnancy increases overall perinatal mortality [15]. Furthermore, the current study gives no clues as to whether calories alone or the balance between calories and other nutrients is responsible for the differing pace of fetal lung maturation in the various nutritional groups. It might even be argued that the nutritional conclusions of the current study are in question because they are mainly based on recordings of weights of the mothers. A number of studies have shown a relation between calorie intake in pregnancy and maternal weight gain [1]. Moreover, cases were carefully excluded from the current study which had non-nutritional disorders that are 
known to affect maternal gestational weight gain [13]. In addition, various internal evidences in the study indicate that the nutritional variables used did reflect gestational nutrition. The patterns of organ and cellular growth in the neonates of presumably undernourished mothers closely resembled the growth patterns commonly found with: (1) uteroplacental disorders that retard fetal growth by restricting nutritional exchange in late gestation $[10,11,13],(2)$ alimentary undernutrition in older infants $[12,13]$. In addition, a wide variety of demographic and other non-nutritional factors had no effect on fetal growth, whereas presumed nutritional factors did have such an influence [13].

Finally, it is important to recognize that both the histologic analyses of lung maturation and the data on hyaline membrane disease are based on infants who died rather than on overall mortality rates. If there were differences in mortality among the various nutritional groups, such differences could have affected histologic maturation and hyaline membrane disease data. For example, better nutrition might lead to lower mortality and the selective survival of those with the more mature lungs. Unfortunately, the mortality rate data needed to critically examine this possibility are not available. Such a bias, if operative, would not influence interpretation of the amniocentesis data of the current study since these latter data were not selected by death.

\section{Summary}

Amniotic fluid lecithin to sphingomyelin ratios and shake test values were greater in undernourished than in overnourished pregnancies after midgestation. There was a similar relation between levels of maternal nutrition and microscopic variables of fetal lung maturity. Using the same anatomic variables, the lungs of female fetuses matured somewhat more rapidly than the lungs of males. Hyaline membrane disease was almost twice as common in neonates who died after overnourished gestations as in those who died after undernourished gestations.

\section{References and Notes}

l. BERGNER, L., AND SUSSER, M. W.: Low birth weight and prenatal nutrition; an interpretative review. Pediatrics, 46: 946 (1970).

2. Clements, J. A., Platzker, A. C., Therney, D. F., Hobel, C. J.,
Creosy, R. K., Margolis, A. J., Thibeault, D. W., Tooley, W. H., AND OH, W.: Assessment of the risk of the respiratory distress syndrome by a rapid test for surfactant in amniotic fluid. New Engl. J. Med., 286: 1077 (1972).

3. Delemos, R. A., Shermeta, D. W., Knelson, J. H., Kotas, R. V., AND AvERY, M. E.: Acceleration of appearance of pulmonary surfactant in the fetal lamb by administration of corticosteroids. Amer. Rev. Resp. Dis., 102: 459 (1970).

4. Gluck, L., AND Kulovich, M. V.: L/S ratios in amniotic fluid in normal and abnormal pregnancies. Amer. J. Obstet. Gynecol., 115: 539 (1973).

5. Gluck, L., Kulovich, M. V., BORER, R. C., JR., BRENNER, P. H., Anderson, G. G., AND Spellacy, W. N.: Diagnosis of the respiratory distress syndrome by amniocentesis. Amer. J. Obstet. Gynecol., 109: 440 (1971).

6. HeARD, C. R. C.: Effects of severe protein-calorie deficiency on the endocrine control of carbohydrate metabolism. Diabetes, 15: 78 (1966).

7. Hytren, F. E., ANd Lerrch, I.: The Physiology of Human Pregnancy (Blackwell, Oxford, 1964).

8. JELLIFFE, D. B.: The Assessment of the Nutritional Status of the Community (World Health Organization, Geneva, 1966).

9. LIGGins, G. C., AND HowIE, R. N.: A controlled trial of antepartum glucocorticoid treatment for prevention of the respiratory distress syndrome in premature infants. Pediatrics, 50: 515 (1972).

10. NAEYE, R. L.: The fetal and neonatal development of twins. Pediatrics, 33:546 (1964).

11. NAEYE, R. L.: Malnutrition, a probable cause of fetal growth retardation. Arch. Pathol., 79: 284 (1965).

12. NAEYE, R. L.: Organ and cellular development in congenital heart disease and in alimentary malnutrition. J. Pediat., 67:
447 (1965).

13. NAEYe, R. L., Blanc, W. A., and Paul, C.: Effects of maternal nutrition on the human fetus. Pediatrics, $52(4): 494$ (1973).

14. NAEYe, R. L., BURT, L. S., Wright, D. L., BlanC, W. A., AND TATTER, D.: Neonatal mortality, the male disadvantage. Pediatrics, 48: 902 (1971).

15. Niswander, K. R., and Gordon, M.: The Women and Their Pregnancies (W. B. Saunders, Philadelphia, 1972).

16. Platt, H. S.: Perinatal mortality and maturity of the Nigerian newborn. (M.D. thesis, University of London, 1970).

17. Shanklin, D. R., AND Wolfson, S. L.: Aqueous estrogens in the management of respiratory distress syndrome. J. Reprod. Med., 5: 11 (1970).

18. We are greatly indebted to Dr. Edward Bowe, Sloan Hospital, New York City, who kindly provided access to amniotic fluid and clinical data from 40 normal pregnancies. Dr. Mary Ellen Avery, McGill University, made valuable suggestions during preparation of the manuscript.

19. This research was supported by Grant HD 06201-02 from the United States Public Health Service.

20. Requests for reprints should be addressed to: R. L. NAEYE, M.D., Department of Pathology, M. S. Hershey Medical Center, Hershey, Penna. 17033 (USA).

21. Accepted for publication November 1, 1973. 